\title{
ACONSELHAMENTOS, BONIFICAÇÃO E COMPROMISSOS: a gestão [precária] do possível com homens autores de violência doméstica ${ }^{1}$
}

\author{
ADVICES, BONUS AND COMMITMENTS: \\ the [precarious] management of the possible with men who commit domestic violence
}

CONSEJOS, BONIFICACIONES Y COMPROMISOS:

la gestión [precaria] de lo posible com hombres que cometieron violencia doméstica

Paulo Victor Leite Lopes

Doutor em Antropologia Social

Universidade Federal do Rio Grande do Norte

paulovleitelopes@gmail.com

Brasil

\section{Resumo}

Esse artigo aborda como determinadas formas de governo são elaborados através da atuação de um "serviço" destinado a "homens autores de violência doméstica". Trago, para tanto, dois aspectos fundamentais dos grupos reflexivos, um dos lócus de observação da minha pesquisa: 1) sugiro alguns elementos que podem ser tomados como constitutivos dos sentimentos de empatia, pertencimento e coletividade, indicando como estes entrelaçam seus participantes e tornam possível a emergência de narrativas comuns em torno de si e das suas experiências de violência; 2) diante disso, desenvolvo uma apreensão a respeito da manifestação de duas técnicas de poder específicas no interior daqueles "encontros", em que a produção e

\footnotetext{
${ }^{1}$ Trabalho apresentado no Grupo de Trabalho 11, intitulado "Gênero, sexualidade e direitos", coordenado por Heloísa Buarque de Almeida (USP) e Regina Facchini (UNICAMP), no VI ENADIR, (Encontro Nacional de Antropologia do Direito), ocorrido entre 26 e 29 de agosto de 2019 na FFLCH-USP (Faculdade de Filosofia, Letras e Ciências Humanas da Universidade de São Paulo). Agradeço o aceite da coordenadoras e as discussões e estímulos proporcionadas por elas e demais participantes do GT.
} 
manutenção de hierarquias entre administrados e administradores tornam-se evidentes, exemplificando um dos aspectos fundamentais à compreensão do Estado: reconhecê-lo como dispositivo contínuo do estabelecimento de diferenças e de relações de dominação.

Palavras-chave: violência doméstica contra a mulher; estado; grupos reflexivos para homens autores de violência doméstica.

\begin{abstract}
This article reflects how some forms of government are developed through the performance of a "service" aimed at "men who commit domestic violence". Therefore, I bring two fundamental aspects of the reflective groups, one of the locus of observation of my research: 1) I sug-gest some elements that can be taken as constitutive of the feelings of empathy, belonging and collectivity, indicating how these intertwine your participants and make it possible an emergence of common narratives around you and your experiences of violence; 2 ) in view of this, I develop an apprehension regarding the manifestation of two specific power techniques within these "encounters", in which the production and maintenance of hierarchies between administrators and become evidence, exemplifying one of the fundamental aspects for the understanding of the State: to recognize it as a continuous device for establishing differences and dominating relationships.
\end{abstract}

Keywords: domestic violence against women; state; reflective groups for men who commit domestic violence; law.

\title{
Resumen
}

Este artículo aborda cómo se desarrollan ciertas formas de gobierno a través de la realización de un "servicio" dirigido a "hombres que cometen violencia doméstica". Por tanto, traigo dos aspectos fundamentales de los grupos reflexivos, uno de los locus de observación de mi investigación: 1) Sugiero algunos elementos que se pueden tomar como constitutivos de los sentimientos de empatía, pertenencia y colectividad, indicando cómo estos entrelazan a sus participantes y lo hacen posible. el surgimiento de narrativas comunes a tu alrededor y tus experiencias de violencia; 2) ante esto, desarrollo una aprehensión en cuanto a la manifestación de dos técnicas de poder específicas dentro de esos "encuentros", en los que se evidencia la producción y mantenimiento de jerarquías entre administradores y administradores, ejemplificando uno de los aspectos fundamentales para comprender la Estado: reconocerlo como un dispositivo continuo para el establecimiento de diferencias y relaciones de dominación.

Palabras clave: violencia doméstica contra la mujer; estado; grupos de reflexión para hombres que cometie-ron violencia doméstica. 


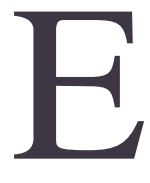

sse texto procura refletir sobre como determinadas "formas de governo", apreendidas etnograficamente através de minha inserção como pesquisador em uma instância administrativa na Baixada Fluminense do Rio de Janeiro, são (re) elaboradas através de um "serviço" destinado a "homens autores de violência doméstica". Nesse sentido, trata-se de uma investigação acerca de processos de formação de Estado, cuja ênfase encontra-se nas práticas, dinâmicas e interações estabelecidas cotidianamente entre administradores - "os técnicos" - e administrados - "os homens" -, bem como entre diferentes instâncias e dispositivos estatais. Procuro compreender tanto a produção contínua do Estado "em ato", privilegiando as dinâmicas constitutivas dos modos de fazer da administração, quanto os modos de subjetivação que, a partir de uma série de constrangimentos conduzidos pelas formas específicas de gestão a que estão submetidos, são operacionalizados pelos sujeitos atendidos pela "serviço" etnografado.

Trago, para tanto, dois aspectos fundamentais dos grupos reflexivos, um dos lócus da minha observação: 1) sugiro alguns elementos que podem ser tomados como constitutivos dos sentimentos de empatia, pertencimento e coletividade,

\footnotetext{
${ }^{2}$ Apesar de sua vinculação ao município, como exploro nesse texto, a proximidade administrativa com o Poder
}

indicando como estes entrelaçam seus participantes e tornam possível a emergência de narrativas comuns em torno de si e das suas experiências de violência; 2) diante disso, desenvolvo uma apreensão a respeito da manifestação de técnicas de poder específicas no interior daqueles "encontros", em que a produção e manutenção de hierarquias entre administrados e administradores tornam-se evidentes, exemplificando um dos aspectos fundamentais à compreensão do Estado: reconhecê-lo como dispositivo contínuo do estabelecimento de diferenças e de relações de dominação.

O ponto de partida para tais reflexões foi a etnografia que desenvolvi ao longo de um ano (Lopes, 2016) em um "equipamento" da rede municipal de assistência social que chamei de Serviço Para Homens $(\mathrm{SPH})^{2}$. Ao longo do trabalho de campo sistemático e diário, seguido por acompanhamento presencial menos cotidiano e através de mensagens eletrônicas e telefonemas, pude observar as rotinas administrativas e outras sociabilidades que se desenrolavam a partir dos seus dois espaços de atuação: a própria sede do "serviço", em um bairro distante do centro do município, e no espaço que ocupavam no interior do Juizado de Violência Doméstica e Familiar contra a Mulher, parte do Fórum, no centro da cidade.

Judiciário borra um pouco dessas fronteiras. Para saber mais, consultar Lopes $(2016 ; 2020)$ 
Apesar de realizarem outras atividades relacionadas e não relacionadas aos Grupos Reflexivos para Homens Autores de Violência Doméstica e Familiar contra a Mulher, nesse artigo centrarei a minha análise nas cenas que se desenrolavam no interior dessa ação. Esses grupos, cuja história é anterior, tornaram-se uma das mais recorrentes formas de administração dos homens autores de violência doméstica após a implantação da Lei Maria da Penha (Leite \& Lopes, 2013; Lopes e Leite, 2013; Lopes, 2016). O encaminhamento dos participantes a esses grupos se dava, sobretudo, através de um instrumento legal chamado "suspensão condicional do processo"3, ou seja, a participação deles nos encontros não era de maneira voluntária, mas como parte do processo judicial que respondiam como réu.

Além dos homens envolvidos em situações de violência doméstica, cerca de treze participantes por grupo, os encontros ainda contavam com a presença dos profissionais que conduziam a ação: Denise, psicóloga, João Carlos ou Joca, advogado, e Pedro, coordenador do serviço e estudante de psicologia ${ }^{4}$. Também

\footnotetext{
${ }^{3}$ Para saber mais sobre tal instituto penal, consultar Leite \& Lopes (2013), diferentes autoras/es em Lopes \& Leite (2013) e Lopes $(2016 ; 2020)$

${ }^{4}$ Além desses atores, durante a minha etnografia os grupos também contavam com a minha presença. Após a autorização prévia-inicial da equipe, no primeiro dos oito encontros era solicitada autorização aos homens para a minha permanência ali. Não obtive qualquer questionamento ou negação, portanto, acompanhei oito
}

autoidentificados como "equipe" ou "técnicos", esses sujeitos eram os responsáveis por conduzirem os encontros, provocando e estimulando debates em torno de temáticas relativas/afins à violência doméstica e familiar contra a mulher, como também por fazer o controle das presenças e notificar o juizado sobre o cumprimento (ou não) da integralidade dos encontros - os participantes deveriam participar de oito encontros quinzenais, com duração de duas horas, na sede do SPH ou no espaço que ocupavam no juizado.

Acredito que através da caracterização dos profissionais que atuam nessa instância, dos atendidos e das relações mantidas entre eles, é possível apontar a dimensão fundamentalmente emotiva que caracteriza não apenas a convivência daqueles sujeitos, mas também concepções fundamentais em torno dessa modalidade de intervenção, suas técnicas e objetivos. $\mathrm{O}$ exame dessa ordem afetiva deve ser apreendido e remetido a um escopo mais amplo de atuação do poder tutelar como forma característica de atuação, distribuição e reconhecimento de direitos no âmbito do estado brasileiro.

grupos, do início ao fim, durante o período de trabalho de campo sistemático. Além da minha observação, recebi autorização e pude gravar os encontros, mediante a afirmação que os dados não seriam publicizados de maneira bruta, ou seja, que eu poderia pequenas alterações para inviabilizar o reconhecimento da autoria da fala ou comportamento descrito no trabalho. 


\section{O grupo como "uma família}

Desde o primeiro encontro entre administradores e administrados, naquilo que os primeiros chamam de "acolhimento", tendo continuidade ao logo dos encontros dos grupos e após o término deles, pude observar determinado esforço por produzir uma imagem acerca do SPH, seus funcionários e dinâmicas. Débora, Joca e Pedro ressaltavam que os grupos não são "para punir", mas, na verdade, para "ajudar" e "orientar", sem, no entanto, querer "mudar o pensamento" dos homens, ou que eles se tornem "outras pessoas". Esses aspectos evidenciam uma apresentação de si que procura valorizar uma perspectiva humanitária, assistencial e acolhedora, através dos verbos "ajudar" e "orientar" e, em conformidade com isso, menos hierárquica e distante, e mais respeitadora das individualidades, quando se revela que não quer "mudar o pensamento" ou ainda que "sejam outras pessoas".

Em um dos encontros, através da narrativa de Fabrício, um dos atendidos, é possível observar a atualização de alguns desses pontos:

\section{Cena 1}

Fabrício conta que tinha um acerto de ver a filha sempre que quisesse, pagava a pensão, "o que ela [a mãe de sua filha] pediu", mesmo não podendo. Contudo, no primeiro fim de semana de vigência dessa combinação, foi impedido de ver a filha. Mais do que isso, relata que a sua ex-esposa o agrediu quando tentou buscar sua filha. Conta que passou na casa de sua mãe e depois foi para a sua casa. Lá chegando, pouco tempo depois, sua mãe chegou avisando: "se prepara que ela foi dar parte de você". "Dar parte de mim? O que que eu fiz? Eu não fiz nada!". Depois de 15 dias chegou uma carta convocando-o para a delegacia. Lá, ao conversar com a pessoa que o atendeu, disse que não agrediu a mãe de sua filha e mostrou as marcas "arranhões" - que ainda tinha das agressões que ela cometeu. Em resposta, o atendente teria dito: "e por que você não veio à delegacia primeiro do que ela e deu parte?” ("Tá vendo... é o que a gente sempre fala", disse Débora). Se eu for na delegacia e depois eu contar pros meus amigos, a primeira coisa que eles vão fazer é abrir a boca e ficar quáquáquáquá. Vão olhar um para cara do outro e quáquáquá, “apanhou de mulher!" Vou ficar como, né? O atendente falou: "Não pode ser assim, não". Débora e Joca cortam Fabrício e ressaltam que "esse é o procedimento" [ir à delegacia e fazer o Registro de Ocorrência], pois, segundo Débora, "muitas vezes acaba que você fica prejudicado e ela não”. Joca destaca que ele ainda "teve sorte", porque o cara ainda "te deu voz"; "tem uns que chega 
assim e: 'meu irmão, você está preso'”.

Fabrício retoma a palavra e diz "Vou ser honesto... Eu tenho muito problemas nas costas, esse não é meu primeiro processo, nem nada. Eu tenho processo de agressão, não só contra a minha ex-esposa, contra um próprio colega meu". E continuou: "Pô, eu não sou assim de levar qualquer desaforo para casa. Eu não aceito levar desaforo para casa, sou ignorante... eu brinco, converso, zoo com todo mundo, sou um bom rapaz de se lidar, mas só que eu também sou de sangue quente...". "É muita coisa pesada contra mim.... Tô correndo risco de ser preso aí porque eu tô vindo aqui”. Sobre a sua vida, ainda contou que passa por "várias provações, todo mundo na rua sabe que eu sou sangue quente". Diante desse cenário, ou desses "problemas", Fabrício conta que encontrou uma solução e compartilha: "O que é que eu faço agora? Eu não bebo mais na rua com ninguém ("Exatamente", diz Joca no meio da narrativa dele), eu fico junto com a minha família em casa. Eu posso até gastar 10, 15, o salário todo, mas compro a minha cervejinha e bebo dentro de casa, faço um churrasquinho ("Isso mesmo, gente, bom exemplo...", comenta Débora). Se eu vou pra um bar, eu vou com a minha família, com a minha mulher, com a minha mãe, com o meu pai, com meu cunhado, com a minha irmã... é isso aí! Junto com eles, ali eu bebo. Acabou ali, eu vou pra casa... porque negócio de ver o sol quadrado, feito meu parceiro ali [mencionando um dos participantes do grupo que esteve preso] já viu, é muito ruim. Débora interrompe e diz: "Por isso que eu te peço que você não pode faltar mais. Você já teve aquela falta (Joca confirma: "éééé"), porque se não você vai ter que repetir como no caso dele [um participante que, por não ter concluído os encontros mínimos, acompanhava o grupo novamente] . (...). Porque o juiz fica perguntando pra gente... E se ele não cumprir com todas essas participações no grupo, ele pode ser preso. É o que eu falo para vocês. Então, não faltem mais, né, gente. Vocês não podem faltar por causa disso".

Por fim, Fabrício conta que no mês anterior "quase fui preso por causa da pensão". Segundo ele, estava "pagando certinho", mas que, no passado, ficou um ano sem pagar, "só de raiva" - porque não vê a filha sempre, não vai às festas etc., apesar de amá-la. (...) Débora esclarece que pensão alimentícia não é para a mãe, é para a filha. $\mathrm{E}$ ela continua: "Tô muito contente de você poder desabafar, contar esses seus problemas... Isso aqui é pra isso, gente ("é pra isso", confirma Joca). Não é para, como ele falou [fazendo referência a uma participação anterior], ficar calado, ficar quieto aqui porque eu estou com muitos problemas. $\mathrm{O}$ nosso objetivo aqui é esse, fazer com que você possa trazer pra gente um pouco dos 
seus problemas pessoais pra gente poder ajudar, para a gente poder orientar, para a gente poder fazer com que vocês possam dar continuidade à vida tranquilamente. Porque, às vezes, um simples fato, essas mínimas violências, elas causam um dano muito grande na nossa vida".

Relacionando a história de Fabrício com a sua, a psicóloga então recupera a sua narrativa sobre a violência que, algumas vezes, pratica no trânsito. E Débora conclui: Porque durante a minha vida eu aprendi essa questão da violência, da mesma forma todos que estão aqui. (...) você aprendeu o que você pode fazer. Então nós podemos desconstruir isso, podemos fazer com que... peraí, eu posso resolver esse problema, mas eu não preciso xingar, humilhar e ofender. Eu posso agir de formas diferentes. Não só com o meu chefe, com os amigos do futebol, mas também com a minha família. Se as pessoas estão me humilhando, eu dei margens para que as pessoas possam fazer. Agora, eu também posso mostrar para eles que tem limites, que eu não quero mais que você brigue, me xingue ou que me chame de 171, porque não cabe a mim... Então você pode colocar limites àquela pessoa sem que você tenha que xingar, falar palavras, humilhar etc.”.

A partir dessa cena, podemos observar a atualização dos aspectos trazidos na citação de Débora de uma forma mais teórica, abstrata, como uma espécie de “dever ser” da interação nos grupos, através do modo como Fabrício elabora a narrativa sobre a violência doméstica em que responde como autor. Inicialmente, é importante destacar que a sua exposição evidencia, através da construção do seu "caso" ou "queixa", um estilo narrativo que parece ser uma característica daqueles encontros e grupos como experiências coletivas, emergindo, a partir disso, uma experiência específica: eles são (ou se tornam) uma “comunidade emocional" (Jimeno, 2010) através das escutas e dos relatos desses "casos". Ainda a respeito dos elos que se conduzem em torno das narrativas e da experiência de situações vividas e/ou contadas sob o espectro do sofrimento, é importante ter em consideração as reflexões de Fassin (2012) para quem o "sofrimento", além de uma dimensão individual, privada, particular, daqueles que sentem/vivenciam, também se constitui como um elemento que viabiliza que os sujeitos se reconstruam através dos outros.

No entanto, é preciso destacar, o sofrimento não é o único elo que permite e/ou conduz ao surgimento dessa comunidade emocional. Entre os fatores que possibilitam que desabafos, lamentações e outras formas de relatos pessoais ocorram, é importante possibilitar que os sujeitos vivenciem um espaço em 
que há uma postura "humanitária, assistencial e acolhedora", não marcado por hierarquia e/ou distância, e que existam configurações específicas, modelares, a partir das quais emerge determinada abertura e/ou disponibilidade para falar e escutar. Essas características, reveladas pela "equipe" como qualidades positivas dos grupos, são também destacadas pelos participantes no encerramento do conjunto de encontros.

Por fim, como fundamento do compartilhamento de experiências dessa comunidade emocional, substrato para que as dicas, elogios, sugestões e esclarecimentos encontrem sujeitos atentos/as e disponíveis a dar e recebê-los, ou ainda que se avalie a experiência como positiva, também emerge uma espécie de sinergia, empatia, proximidade entre os sujeitos que parece viabilizar uma interação mais próxima entre eles. A condução dos grupos a partir de uma espécie de informalidade, que pode ser pensada como produto e produtora de empatia e identificação, é feita através de um cotidiano em que brincadeiras e jocosidades podem se constituir como uma importante linguagem de comunicação entre os sujeitos. Ao mesmo tempo, o reforço à ausência de distâncias, hierarquias ou fronteiras entre eles, pode ser feito quando os sujeitos se esforçam em mostrar-se iguais, compartilham experiências pessoais, de êxito ou não, mostrando-se inclusive falhos, sejam os técnicos ou os homens. Sendo, para utilizar uma metáfora a que Débora sempre recorria, "uma família".

Não obstante a centralidade que o compartilhamento de experiências construídas como produtoras de sofrimento e vitimização desempenha naquele lugar, vale destacar, mais uma vez, que não são só essas que constituem aqueles espaços e os temas de troca. A presença de perguntas e dicas a respeito dos casos dos outros, as narrativas de experiências particulares independente da relação que os reúne ali - e a existência de brincadeiras e piadas, evidenciam um pouco daquilo que Débora sintetiza como "família". Revelam a existência de algum nível de intimidade e abertura para que, a despeito dos desconhecimentos, distâncias e diferenças entre si, os sujeitos possam saber das vidas uns dos outros e, ao mesmo tempo, sugerir comportamentos, atos, soluções, conformando certo espírito comunitário e de cuidado. Compartilhar as suas experiências, seja como forma de apenas narrar algo que viveu ou sugerir o acontecido como uma situação que "serve de exemplo", ou ainda acionando determinada ordem da jocosidade, revela algum grau de intimidade e afinidade nas relações ali tecidas. 
Essa

dinâmica-atmosfera

desenvolvida nos encontros é fundamental à manifestação das "formas de aconselhamento" nos grupos. Esse aspecto, no entanto, marca uma clara distinção dos modos como essa técnica de governo se manifesta no SPH e no Tribunal cordobés, campo a partir do qual Lugones (2012) formulou essa noção. Contudo, se, como tentei exemplificar acima, há um engajamento dos técnicos e a conformação de um tipo de sociabilidade que conduz a uma compreensão e elaboração do grupo como um espaço em que as hierarquias se diluem, "onde todos são iguais", há, por outro lado, outra operação que, de modo sutil, não apenas reforça, mas se funda em assimetrias entre técnicos e atendidos. $\mathrm{E}$ isso tem relação com tais "fórmulas de aconselhamento". Vejamos a seguir.

\section{Aconselhamentos}

Ao realizar a sua etnografia a partir do Tribunal Prevencional de Menores de Córdoba, Lugones (2012) identifica duas "técnicas de gestão", isto é, atos que produzem/são a manifestação do exercício do poder administrativo-judicial e de materialização da presença estatal, que

\footnotetext{
5 Existem algumas diferenças nas formas como essas técnicas são produzidas na instância etnografada por Lugones (2012) e por mim (Lopes, 2016). Tais aspectos
}

caracterizariam a relação entre administrados e administradores no cotidiano das suas interações durante o seu trabalho de campo: as "formas de aconselhamento" e a "fórmulas de compromisso" $"$. A autora argumenta que as primeiras constituem uma operação habitual das administradoras judiciais, caracterizadas por serem mais próximas da figura do "conselho" que do “assessoramento técnico", este último, segundo destacado, previsto "normativamente". Em comum entre esses três atos, o reconhecimento de alguma assimetria entre aquele que "oferta" e aquele que "recebe". Essa seria justamente a diferença que funda esses gestos, dado que é preciso reconhecer essa "autoridade" e/ou "legitimidade", não necessariamente jurídico-legal, entre esses dois atores.

Esse aspecto, portanto, reorienta um pouco as relações que destaquei como representativas de um esforço de diluição de hierarquias entre técnicos e atendidos. Se, por exemplo, o terreno das brincadeiras poderia fazer crer, ou estabelecer, um terreno de igualdade, a expressão continuada das "formas de aconselhamento", por outro lado, as reelaboravam em outra direção, ainda que de forma discreta, diluída e menos

são discutidos na tese que deu origem a esse artigo, subtraio aqui em decorrência da limitação do espaço. 
perceptível. O cerne da compreensão, no entanto, deve residir no reconhecimento de que se trata de uma técnica capaz de garantir o exercício do "poder administrativo" e, através deste, a materialização da presença estatal no cotidiano dos sujeitos.

Um tema recorrente nos grupos, como pude observar a partir de diversos encontros, refere-se às possibilidades de enfrentamento ou os caminhos e soluções para lidar com dificuldades, tensões e conflitos nos relacionamentos. O "diálogo", "a conversa", “a comunicação" etc. são apresentados pelos técnicos - e pelos artefatos acionados, como os vídeos e as dinâmicas que são utilizados nos encontros como estratégias fundamentais à prevenção de violências e à realização de uma vida familiar saudável e harmônica. Esse cenário, tema e abordagem, se repetiam ao longo dos encontros, veiculando ou produzindo, cotidianamente, "formas de aconselhamento" como os trazidos nesse relato. Joca e Debora, respectivamente, desenvolvem uma conversa-aconselhamento em torno de dinâmicas familiares.

\section{Cena 2}

Joca: Porque eu quero perguntar para vocês, a maioria aqui tem filhos, eu queria perguntar aqui para vocês se a maioria tem o hábito de parar, sentar, chamar os filhos, conversar sobre como eles se sentem com isso... vocês têm esse hábito? (...) No convívio, agora falando sério... naquele mesmo outro vídeo, que a Dra. Adriana fala [refere-se ao documentário "Silêncio das Inocentes" exibido anteriormente], nós perdemos o hábito de fazer uma refeição juntos. Pelo mercado de trabalho, às vezes a mulher trabalha também, tanto quanto o homem, finais de semana, hoje é comum, né, quase todas as casas, tem mais de uma TV. Então, um quer ver futebol, pega o prato e vai ver futebol; outro quer ver Sílvio Santos, pega o prato e vai ver Sílvio Santos. E não tem mais aquele almoçar... [“"na mesa", em uníssono vários homens completam; “reunião", disse outro depois].

Um homem comenta que tem três televisores em casa.

Joca: Ainda bem, né? O país melhorou nesse sentido, mas, em contrapartida, nós estamos, realmente, perdendo esse hábito de sentar... e ali é o momento pra conversar... falar das nossas necessidades... e hoje tá muito difícil...

Débora: E também saber o que se passa com os filhos, né?! Porque é importante você dialogar nesse momento de calma... porque, às vezes, ele também tá estudando, ou a menina, enfim, se for pequeno, se for adulto, adolescente... não tenho tempo de saber o que que está acontecendo. É muito fácil você é... é... observar o comportamento do filho da seguinte forma ("Boa ideia, hein?!", comenta 
alguém). 'Pai, posso ir no shopping, no show... em algum lugar?', 'Ah, tudo bem. Pode!'. Mas chega 10, 11, meia-noite ou no dia seguinte... e o pai não quer saber. 'Porque que você chegou tarde? Eu falei que era pra dez horas tá aqui!' [entonação que busca simular rigidez]. Não tenho diálogo, saber o que está acontecendo... 'você foi para o shopping? Com quem você foi? Quem são seus amigos?'. Não que queira que apresente [os amigos do filho], mas mostrar o amigopai, o interesse-pai, e não com agressividade, querer saber... Muitas das vezes os próprios filhos estão usando drogas e os pais não sabem. E a única coisa que faz é agredi-lo fisicamente ou verbalmente. Se for a filha mulher, geralmente, xinga: 'sua prostituta, sua isso, sua aquilo, isso não é hora de estar na rua...' Enfim, não tem esse diálogo. Quando é filho homem, 'seu sem vergonha, seu vagabundo ('É...' diz um homem), vai estudar...' mas não quer saber o que está acontecendo. Muitas das vezes pode ter acontecido com a gente na infância. Na nossa fase de adolescente, o pai e a mãe não tiveram a oportunidade de sentar e conversar pra saber o que está acontecendo com a gente. E a gente fica pensando: meu pai não fez isso comigo, por que que eu vou fazer com meu filho?

Em outro grupo e encontro, enquanto

\footnotetext{
${ }^{6}$ A prescrição de comportamentos e interditos específicos que, quando descumpridos, podem acarretar privação de liberdade, é o ele entre as duas medidas nessas falas, ou "aconselhamentos", elaborados pelos técnicos. Para
}

realizavam uma das dinâmicas disparadoras, a emergência de algumas narrativas recentes sobre violências praticadas dava a oportunidade para que os técnicos os lembrassem de alguns dos mecanismos que os governam, em especial a "suspensão condicional do processo" e as "medidas protetivas" $"$. Ao mesmo tempo, indicavam os "riscos" que eles correriam caso se envolvessem em novos conflitos ou outros processos. Como alguns desses relatos começavam com "há pouco tempo", "no mês passado", “outro dia”, logo que a violência era narrada havia a intervenção imediata questionando o ato e "aconselhando" que, nos próximos anos, "é pra ficar no sapatinho".

\section{Cena 3}

Valter: Essa semana eu quase caí no tapa com um motorista lá, que me fechou. Eu trabalho em casa de material, como motorista, tô saindo com o caminhão, aí o cara vai lá e me fecha. Ah... pra quê? Já tava irritado com o calor que fez na semana toda e comecei a xingar ele. Aí ele foi e revidou. Nisso que ele revidou, eu falei: 'desce do carro e vamos resolver que nem homem'. Aí começou aquela discussão de troca de insultos. Aí eu pensei: quer saber, isso não vai dar em nada! Peguei e entrei com o

saber mais sobre o uso de tais dispositivos na administração da violência doméstica e familiar contra mulher, consultar diversos textos em Lopes \& Leite (2013) ou ainda Lopes (2016). 
caminhão, fiz o contorno e fui embora fazer as minhas entregas.

Joca: A melhor coisa que você fez...

Débora: Exatamente! ${ }^{7}$ Até mesmo porque você tem que entender aquilo que a gente fala aqui: quem tem a suspensão condicional do processo, se envolver em qualquer discussão, como no caso do risco que ele correu...

Humberto: Agrava a situação?

Débora: Com certeza!

João Carlos: Independentemente se for mulher ou não.

Humberto: Por que o cara não é mais primário?

Joca: Não, ele é primário... Todos vocês que estão aqui sob a suspensão condicional, não foram condenados a nada. Portanto, todo mundo é primário, entendeu? Mas vocês estão sob a suspensão condicional. Se amanhã, eu canso de explicar isso, até mesmo uma briguinha dessa de bar mesmo, de futebol, se sair uma briga, uma confusão, que der polícia e for feito o registro, quando bater no JECRIM, não vai para a violência doméstica, mas vai pro JECRIM, quando eles levantarem e verem que você está sob a suspensão

\footnotetext{
${ }^{7}$ A narrativa de Valter e as reações de Joca e Débora, ainda que nesse trecho tenham se dado de modo bem curto, constitui um dos muitos momentos em que se revela uma modalidade específica de gestão no interior não só dos grupos, mas do SPH: o elogio, a bonificação,
}

condicional do processo, o juiz pode muito bem cancelar essa suspensão e prender, entendeu? Porque durante esses dois anos que vocês têm que assinar lá no cartório, vocês têm que ter uma vida bem quietinha. Eu até aviso a quem gosta de tomar umas cervejinhas, compra e leva pra beber em casa... que é para não ficar no bar que sempre tem um papo ou outro, que pode surgir uma confusão... compra cervejinha no mercado e bebe em casa, tranquilo...

Débora: Pelo menos por esse tempo, né?

Joca: Não é necessário deixar de frequentar o bar, não, mas tem que tomar muito cuidado. Vamos supor o caso dele ali [refere-se a Cláudio, que contou pouco antes sobre essa situação]: jogou a garrafa no rapaz! Se tá certo ou errado, é outra história (Débora fala ao mesmo tempo: “errado está!"), mas acerta o rosto do rapaz, certamente, certamente, será feito o registro de ocorrência! Iria perder a suspensão condicional do processo, entendeu? Tem que se pensar muito...

Cláudio: Mas na hora não pensa, diz.

Débora: Exatamente.

Joca completa: O problema é esse!

o reconhecimento ou chancela de gestos considerados positivos/exemplares. A seguir trato, em específico, dessa expressão e de sua relação com o escopo analítico que venho empregando aqui. 
Em suas reflexões, Lugones (2012) ressalta que as "formas de aconselhamento" transitam e articulam-se entre a admoestação e o aviso, a advertência e a sugestão, como exemplificado, seja em torno das consequências familiares (Cena 2), ou nas jurídicas, trazidas a partir da narrativa de Valter (Cena 3). Para tanto, em seu argumento, além das gramáticas indicadas acima, há evidentemente uma relação saberpoder a autorizar, fundamentar e legitimar o reconhecimento das administradoras como aconselhadoras, ainda que, na operacionalização cotidiana, seja a "boa intenção" que dê a forma. Há também um léxico comum entre o comportamento aconselhado e a moralidade compartilhada com o sujeito para quem ele se destina. Isto é, uma correspondência entre o conteúdo da recomendação e as crenças/concepções de quem as recebe, que opera para conferir autoridade/legitimidade àquela interação.

Em razão disso, é oportuno observar a plasticidade das temáticas alvo do "aconselhamento". Se, em princípio, a legitimidade emergia a partir do campo de formação e da temática em questão, isto é, advogado e psicóloga eram autorizados a tratar de assuntos relativos à violência doméstica e seus correlatos mais diretos, no decorrer dos encontros era possível reconhecer a incidência sobre uma ampla gama de temas e espaços de administração e/ou aconselhamento. Além das referências à diversão e consumo de álcool exemplificadas através da cena 1 exposta acima, em que Fabrício revela as suas estratégias para "evitar confusão"- também pude acompanhar, da parte de técnicos, críticas a determinados estilos musicais considerados de qualidade inferior, como forró, funk e pagode, e também recomendações sobre a importância e o valor da leitura. A cena a seguir demonstra uma das manifestações a que me refiro:

\section{Cena 4}

A partir de um caso de violência trazido no programa Globo Repórter exibido no encontro do grupo, Joca menciona um homem "que não aceitou o sucesso da esposa". Tadeu, a partir disso, fala que a mulher foi mais inteligente que $o$ cara - mas que os dois, homens e mulheres, são igualmente inteligentes. Joca também fala que possuem a mesma capacidade, mas uns desenvolvem mais e outros menos. A conversa continua em torno do tema inteligência.

Joca cita uma música de Raul Seixas em que ele fala que o ser humano usa $10 \%$ de sua inteligência e emenda: "Mas agora você vê, e aqui não vai nenhuma crítica pessoal, até porque eu estou inserido nesse contexto, tem muitos de nós que... Quem hoje não assiste aquele programa "corta pra 
mim, Percival"? [Referência ao programa Cidade Alerta, exibido pela Rede Record de Televisão, e ao bordão do seu então apresentador, o jornalista Marcelo Rezende]. Aquele cara nojento fala... Cara, se você botar a tua televisão no canal dois, você vai ver a programação da TVE, TV educativa. Lá não vai ter ninguém falando "corta pra mim". [Risos do grupo]. Aí você vai ficar vendo aquilo, você vai ficar bitolado... Como até pouco tempo atrás era aquele "escracha!" [referência ao programa Cidade Alerta, exibido pela Rede Record de Televisão, e ao bordão do seu apresentador, o então deputado estadual Wagner Montes]. Entendeu? Então, se você procurar desenvolver o teu lado intelectual, não é a escolaridade; escolaridade é diferente do cara desenvolver a questão intelectual dele. Pô, bota lá na TV Brasil, no canal 2 , que você vai desenvolver... Você até pode ver o "corta pra mim", mas não veja tudo, veja uma parte [Risos]. Entendeu? Quer ver?? Quem daqui ouve "A voz do Brasil"? (Tadeu diz: "Não, realmente, eu não tenho ouvido..".) Cara, aquilo ali rege a nossa vida! ("Eu não tenho ouvido", diz outro) Ninguém ouve aquilo... ("Eu tô sem rádio", justifica Tadeu) Aquilo ali você sabe notícias do Planalto, do que a dona Dilma tá lá assinando neste momento... e o cara quer saber do Flamengo! Eu também quero saber do Flamengo, que eu sou flamenguista, mas eu quero saber como é que estão as outras situações.
Ante aos comentários e recomendações de João Carlos, Tadeu se justifica e reage: Não, uma coisa que, realmente, antes de sair do trabalho eu vejo, aquela "última sessão" [série de desenhos infantis exibidos no início da amanhã no SBT], eu vejo os desenhos, depois começa o... o... telecurso! Aí aquilo ali, com certeza, eu não vejo ele todo, porque não dá tempo de ver ele todo, mas eu vejo uma boa parte dele... Ali eu tô exercitando a minha mente!

A partir da cena acima é possível identificar outra característica das formas de aconselhamento, além das já mencionadas: a existência de determinada confluência moral entre aconselhador e aconselhado; trata-se da existência de “crenças compartilhadas” (Lugones, 2012, p. 187) entre ambos. Aos aconselhamentos de consumo de programas televisivos "educativos" e à necessidade de “desenvolver a inteligência", Tadeu reage, não apenas reconhecendo sua falha ("Realmente, eu não tenho ouvido") e se justificando ("Eu tô sem rádio"), mas também apresentando uma opção, um comportamento positivo similar ao que João Carlos sugeria, portanto, reconhecendo a legitimidade e o valor da sugestão (ele assistia "o telecurso").

Ainda seguindo as discussões e formulações desenvolvidas por Lugones, parto da compreensão que as "formas de 
aconselhamento" transitam entre diferentes questões e amplificam seu campo de atuação não apenas em razão da porosidade de temáticas que se articulam em torno de emoções, da moral e do direito, mas também por outra característica que as fundam: essa técnica de poder é uma expressão do "poder tutelar", conforme proposto por Souza Lima (1995), e, por outro lado, constitui0se também como uma técnica de "menorização" (Vianna, 2002) das suas administradas. Ao identificar essa técnica de gestão, Lugones (2012) ressalta a dimensão eminentemente pedagógica, que, entre outros aspectos, permite reconhecê-la em diálogo com os autores indicados acima. Os mecanismos tutelares, ou o
"poder tutelar", inscrevem-se no imbricamento da soberania e da disciplina, como modalidades de poder tal como formuladas por Foucault $(2000 ; 2008)$, dado que se sustentam em uma assimetria fundamental no que se refere a direitos, mas, ao mesmo tempo, em uma série de atuações que acionam diferentes técnicas de regulação de comportamentos. A tutela, portanto, está relacionada a esse duplo movimento: ela depende que determinados sujeitos reconheçam a sua subordinação a outros sujeitos e, ao mesmo tempo, demanda que estes outros sujeitos assumam o dever/responsabilidade de conduzir os primeiros, e, desse modo, garantam (ou produzam) a eficácia da gestão dessa população.

Nos encontros entre 0 Juizado e as casas, ou ainda entre o Estado e a família, a regulação de tais comportamentos e a condução dos sujeitos assume, a partir das formulações de Vianna (2002) e Lugones (2012), contornos daquilo que as autoras chamam de "menorização". Recorrendo a exemplaridade da figura do "menor", e destacando que a "menoridade" é uma relação de dominação, Vianna (2002, p. 7) argumenta que:

"Ser menor é, sobretudo, encontrar-se em posição de autonomia parcial, por quaisquer motivos que sejam considerados operantes em um dado momento e em uma dada configuração social. É, nesse sentido, ser compreendido como estando em situação de ter alguém que responda por si, que seja seu responsável, permanecendo incluído em um conjunto de relações de autoridade em posição subordinada, ou seja, não apenas colocado em meio a relações de interdependência, mas, sobretudo, de assimetria. (...) Menores podem ser mulheres, escravos, filhos não casados, agregados, loucos, índios, enfim, todos aqueles que, em uma configuração social específica, sejam compreendidos como incapazes (ou relativamente incapazes) de responderem de forma integral por seus atos. Os que precisam de um tipo peculiar de proteção: a proteção de estarem submetidos à autoridade responsável de outro indivíduo ou conjunto de indivíduos.”. 
A partir de tais considerações, é importante destacar esse duplo aspecto que conforma não só a emergência dos aconselhamentos, mas a ampla e diversificada variedade de temas e questões que lhes são objeto: 1) o reconhecimento dos administradores, daqueles que conduzem ou que são os tutores de sua superioridade com relação aos seus administrados/tutelados, nesse caso, não apenas nos temas caros/relativos à violência doméstica, mas em torno daquilo que é possível pensar como construção da pessoa, daí a riqueza da relação com a "menorização"; e 2) de maneira articulada a isso, o dever moral e administrativo dos administradores em "assistir, (acompanhando, auxiliando e corrigindo) a conduta do tutelado, de modo que o comportamento deste seja julgado adequado" (Pacheco de Oliveira, 1988, p. 224).

\section{Sobre bonificação e fórmula de compromisso}

Outra forma de atualização daquilo que Souza Lima (1995) chamou de "poder tutelar", ainda que contenha dimensões distintas, é (re) produzida próximo desse modelo das "formas de aconselhamento". Através de momentos como o de Valter (cena 3), ou de passagens curtas como aquelas trazidas a seguir na cena 5, acredito ficar clara a intencionalidade de incidir sobre as condutas a partir dos valores personificados pelos técnicos. A um comportamento considerado bom, são direcionados elogios, produzindo determinado reconhecimento positivo sobre o modo como o sujeito atua, portanto, sobre aquilo que ele é. Do mesmo modo, mas em situações opostas, críticas ou questionamentos tinham como finalidade pôr em xeque algumas atitudes, revelando aquilo que é considerado legítimo e o que não é. Ambos os comportamentos, performados no cotidiano, acionam elementos da dimensão disciplinar presente nas "formas de aconselhamento". Por outro lado, o reconhecimento da autoridade/legitimidade dos técnicos como avaliadores reforçam os aspectos relativos à distribuição do direito, característicos do poder soberano. Um exemplo disso foi trazido através da narrativa de Fabrício (cena 1), no início desse artigo, quando ele conta que deixou de "beber na rua".

Ainda que, como venho sugerindo, nem sempre essa orientação de conduta se dê sob a forma de um aconselhamento direto, é possível notar, a partir da formulação das "bonificações", o investimento dos técnicos em direcionar os comportamentos, emoções e posturas consideradas razoáveis ou mais "seguras" 
não apenas para o sujeito que faz a narrativa, mas, considerando a presença dos demais ouvindo as intervenções do administrado e do (s) administrador (es), extensivamente a todos. Outro exemplo de atualização como essa, pode ser observado a partir da relação que se estabelece entre o testemunho de Vanderlei e as intervenções de Débora e João Carlos que, na cena que segue, não tratam dos comportamentos a partir das noções de "perigo", "risco" ou "segurança", mas em torno das "vantagens", "ganhos", "melhorias".

\section{Cena 5}

Vanderlei: Eu tenho uma coisa pra falar, eu acho que a minha história de vida é bem bacana, desde que ocorreu essa tempestade toda comigo. Então a minha história de vida hoje tá sendo bem bacana, porque, assim, tem um ditado que a gente só fecha a porta quando é assaltado, né? Então, assim, a gente voltou, no meu caso, com a minha mulher, a gente voltou... Eu acho que o ser humano é muito ignorante, precisa, às vezes, apanhar um pouco para aprender na vida, para saber onde errou, onde tá errado... Então, depois que a gente voltou, a nossa relação tá bem bacana mesmo, entendeu? Tanto da parte dela como da minha parte também. Ela tá me respeitando bastante. Eu também tô respeitando ela. A gente tá contribuindo, junto, com o nosso filho. $\mathrm{O}$ diálogo da gente mudou bastante... É como se a gente tivesse vivendo uma nova lua de mel, tá entendendo?

Débora: Olha a importância do que você tá falando: "ela tá me respeitando e eu estou respeitando ela!". Isso é fundamental em um relacionamento...

Vanderlei: Então, assim, às vezes a gente precisa apanhar um pouco para acordar pra vida. Saber onde que errou, qual foi a forma que você criou aquele problema, pra chegar naquele ponto que chegou. Então, cara, eu acho assim, sei lá, é bacana você poder respeitar as pessoas, saber a importância do respeito, também ser respeitado, e saber que aconteceu aquilo porque você foi, simplesmente, a pessoa que não teve um entendimento da... da... da... de tudo, né? Do começo até o fim, né? Por falta de, por ignorância, criou esse problema, de chegar até esse ponto. Assim, agora, hoje, praticamente a minha vida tá superando cada dia mais. Quer dizer, a gente tá vivendo uma história de vida, praticamente. A gente voltou, nosso filho é uma, tem outra autoestima, né, dele ver a gente bem... Ele ri, ele brinca com a gente, a gente passeia junto, a gente não fica mais aquela coisa de ficar um esperando pelo outro, não?! Chega o fim de semana, ela trabalha e eu também trabalho, vamos passear? Vamos! Nós pegamos nosso filho... 
Débora: Olha a outra importância do que ele disse: É, a partir do momento que ele ficou bem com a mulher, os filhos também ficaram bem ("Reflete nas crianças", comenta outro atendido) reflete nas crianças... Por mais que estejam morando juntos ou não, "ah, mas eu não estou mais morando com ela". Tudo bem, não é o caso deles, eles estão juntos, mas a importância de se dar bem com a mãe do meu filho faz com que ele possa se sentir bem: "Ah, tudo bem, meu pai e minha mãe não tão morando juntos, mas eles estão bem”. Isso é importante para aquela criança.

Vanderlei: Então, como a senhora falou, meu filho, ele sofreu muito. Não só ele, como eu, ela também...

Joca: Mas a criança sente muito mais.

Vanderlei: Sente muito mais, não tem a presença do pai, da mãe muito pouco, porque também, em casa, ele sempre ficou mais com a avó dele, do que comigo ou com ela. Ele não queria mais ficar com ela, porque ela é um pouquinho mais agressiva com ele, COM ELE [enfatizou Vanderlei]. Porque ela quer educar de uma forma, sabe, muito rígida, até eu concordo, porque não pode deixar é...

Débora: É tem que ter limites (Vanderlei repete: "Tem que ter limites"). Não pode deixar, nem apertar muito e nem liberar muito.

Vanderlei: $\mathrm{Eu}$ sou mais aquele paizão bobo, né, que brinco, deixo, só grito... É mesmo. Às vezes quando não é o pai, é a mãe que gosta de ser mais agressiva. Eu sou mais aquele bobão de só falar, gritar e deixar pra lá. Ela não, ela já corrige... Então, aí o garoto sofria muito, ficou magrinho, sabe, abatido... Depois que a gente voltou... Poxa, tem que ver... Uma bênção!

Débora, utilizando a fala de Vanderlei, ressalta que as mesmas alterações, diante dos mesmos comportamentos e efeitos consequentes, também foram observadas no filme que viram naquele dia ["Era uma vez uma família"]. Conclui ressaltando, a partir de uma cena do filme e do próprio relato de Vanderlei: “As crianças ficaram felizes quando o pai brincou". Joca, cortando a fala de Débora no meio, pergunta se ele, Vanderlei, tinha medidas protetivas. Vanderlei respondeu que tinha, mas que a esposa "já tirou”. Joca, em tom de explicativo e de aviso, encerrou: "Dá cana!".

Ainda que tenha indicado a operacionalização da "bonificação" através dos elementos que a aproximam ou vinculam às "formas de aconselhamento", é interessante pensá-la a partir de algumas configurações de outra "técnica de gestão" identificada por Lugones (2012): a "fórmula de compromisso". Em sua conceituação a respeito da técnica, a autora revela que ela se manifesta em um 
"panorama normativo cambiante", em que a possibilidade de perda da guarda do "menor" se constitui como uma "forte presença", conduzindo, desse modo, a assunção de obrigações e compromissos, da parte das administradas, visando não só a manutenção da guarda “do menor", mas, ao mesmo tempo, o seu deslocamento da posição "menorizada". Apesar da nomeação de "compromisso", a autora destaca que isso não significava que, após firmados, os sujeitos se engajariam em seu cumprimento, dado que a sua realização encontrava-se na própria enunciação (e no seguinte registro nos “autos" do processo) $)^{8}$. Lugones (2012, p. 198), ao retratar os elementos que compõem tais fórmulas, argumenta:

Estas fórmulas llevan a (re)considerar como compatibles dos dominios tenidos como antitéticos: el de la fe y el del cálculo. Habría un cálculo presumidamente racional sobre las medidas que se tomaban, de lo que se consideraba admisible $o$ inadmisible, al mismo tiempo que la técnica de formular compromisos introducía la fe, la creencia en la palabra empeñada, conformando una incumbencia mixta, sin por ello alejarse del "derecho" que, desde sus orígenes romanos tendría como "lo constitutivo no el hacer, sino más bien el pronunciar" (Benveniste apud Supiot, 2007: 83). Las fórmulas de compromiso se cifraban en un "dar crédito" de la

\footnotetext{
${ }^{8}$ A autora afirma que "No se trataba de acuerdos ni de convenios sino de fórmulas a partir de las cuales se extendía virtualmente la acción y presencia estatal,
}

administración a la palabra empeñada por los administrados y su correlato, asumirse "acreedor" del cumplimiento de alguna "obligación".

A partir de tais discussões, é possível compreender a "bonificação" como uma operação que, ainda que guarde as características que indiquei a respeito das “formas de aconselhamento", também observa algumas propriedades das "fórmulas de compromisso". Entre "a fé e o cálculo", é possível observar a constituição mútua entre administrados e administradores (ou entre atendidos e técnicos), articulada a partir do acompanhamento das condutas daqueles sujeitos.

A administração no SPH caracteriza-se por uma atuação continuada, durante um período de tempo previamente delimitado e reconhecido por todos, além de ser executada, de certa maneira, após a conclusão do processo judicial. Assim, por exemplo, se comparado com a etnografia de Lugones, o espectro da "espetacularização da soberania" (Vianna, 2002), expresso naquele contexto através da possibilidade de cassação da guarda do "menor", é (quase) nulo. Nesse sentido, é oportuno questionarmos sobre $\mathrm{o}$ caráter da emergência desses autorelatos, que se referem à exemplaridade das ações (ou

reproduciendo obligaciones que posibilitaban que se tomaran determinadas medidas y que se arribara a (in)ciertas (re)soluciones" (Lugones, 2012, p. 194) . 
desejo) dos administrados nesse contexto, e as reações suscitadas a partir deles.

\section{Notas finais}

Como indicado acima, Lugones (2012) parte das reflexões de Vianna (2002) que, refletindo a respeito da gestão da menoridade a partir de processos judiciais e da implantação do Estatuto da Criança e do Adolescente (ECA), defende que é na dinâmica da "complementariedade" e "coextensividade" entre o juizado e as casas que a administração estatal se organiza. Essa, segundo a autora, centra-se "na busca por soluções administrativas que garantam a autoridade da própria administração através não do controle, fiscalização ou repressão das relações que compõem as unidades domésticas, mas de variadas formas de negociação, conciliação e reforço dessas mesmas relações" (2002, p. 28). Sob tal perspectiva, portanto, essas técnicas, não apenas a "bonificação" e a "fórmula de compromisso", mas também as "formas de aconselhamento", iluminam outra apreensão da relação entre administração e casa, centrada não no conflito ou na tensão, mas na reconciliação, em uma espécie de acordo entre as partes, diferente do que havia sido postulado por parte da literatura

\footnotetext{
${ }^{9}$ A respeito das reflexões de Vianna (2002) e de sua
} apropriação para a identificação das "formas de a respeito dessa relação. Ainda seguindo Vianna, tal reconciliação pode ser pensada não somente entre esses dois atores, mas, ao mesmo, entre o Estado e a sua "promessa", dado que é através desse arranjo que a sua eficácia é produzida ${ }^{9}$.

O que se veicula com as situações de relato-bonificação é, na verdade, através de um único contexto, a expressão de uma dupla manifestação da eficácia dessa administração estatal: ela anuncia-se eficaz não só pela firmação de um compromisso, através da promessa (e efetiva) incorporação de novos/outros comportamentos nas práticas dos sujeitos, mas, ao mesmo tempo, por tais "mudanças" ou ações se constituírem em torno de condutas longa e constantemente "aconselhadas" nos diferentes encontros. A partir dessas narrativas marcadas pela bonificação, ainda, é possível conduzir a novas "formas de aconselhamento" e ao agenciamento de "compromissos", reconhecidos e instituídos pela exemplaridade de um afim, isto é, de outro participante do grupo.

Partindo das considerações expostas acima, é possível reconhecer em tais operações um agenciamento importante não só para a eficácia da administração estatal e da própria autorização/legitimidade daquele

aconselhamento" e das "fórmulas de compromisso", ver Lugones (2012, p. 199). 
espaço, seus atores e técnicas na condução ou administração daqueles sujeitos, mas também das próprias formas de ser, existir e se comportar como retratadas naquilo que é exemplificado. Esse substrato é fundamental não apenas para os arranjos que se produzem em torno "do Estado", mas para a consolidação e força de um modelo de atuação centrado, como destacou Vianna (2002), na coextensividade e complementariedade entre tal administração e seus administrados.

Ao observarmos a fixação dessas narrativas em torno da assunção e do compromisso de novos comportamentos e gestões de relações pessoais, é oportuno retomar os argumentos de Vianna (2002) a respeito da atuação das assistentes sociais na condução de processos judiciais e o modo como modelavam as suas avaliações e intervenções em torno do reconhecimento daquilo que seria "o possível" para aqueles sujeitos e para as suas unidades domésticas. A partir do exame dessas operações, a autora ressalta que uma análise sobre os modos como os casos eram geridos revela que "os arranjos, conciliações e acordos promovidos" eram definidos "a partir de sua preocupação em obter eficácia na gestão de inferiores - as unidades domésticas possíveis em lugar das famílias modelares” (2002, p. 65).

O que se revela, portanto, tomando essa perspectiva de análise, é a elaboração de uma gestão do possível no interior da violência doméstica. Sem dispor dos mecanismos de controle ou fiscalização sobre esses sujeitos, seus comportamentos ou atitudes, mas tendo em seu horizonte de obrigações a garantia da integridade às mulheres e, ao mesmo tempo, o dever de controlar as situações de conflito, seja em sua forma punitiva ou preventiva, o Estado deve promover e dispor de métodos de produção e aferição de sua eficácia em torno de tais questões.

Sob os limites de uma administração conduzida em torno da precariedade, uma das estratégias acionadas é a identificação e produção de vínculos de parceria com os sujeitos, de modo que eles possam se tornar aliados ou cogestores dessa administração no interior de determinadas relações, conduzindo, portanto, à operação de uma lógica de complementariedade e coextensividade entre o Estado e seus administrados. No entanto, ao mesmo tempo em que se estabelecem tais relações, essa mesma administração interage e produz esses sujeitos em torno das suas insuficiências e inabilidades em lidar com as questões em que ela, nesse processo, os converte em partícipes da gestão.

A atuação que aqui emerge desse arranjo, portanto, não se dá em torno da clássica leitura que observa a ação estatal sobre os sujeitos, procurando disciplinar e 
conformar as suas atitudes em torno daquilo que reivindica como o ideal, mas arranjos tácitos em que o que se postula é o ordenamento possível aos sujeitos e ao Estado, em que o que se coloca como horizonte não é a obediência, a incorporação de modelos ideais de família ou relações afetivas, mas, na verdade, que aqueles sujeitos, e suas relações, não deem mais problemas. O que se espera, portanto, é uma pacificação dais relações, de modo que o Estado não seja, mais uma vez, demandado em torno das mesmas ${ }^{10}$.

\section{Referências bibliográficas}

FASSIN, Didier. Humanitarian Reason: $a$ moral history of the present. Berkeley, Los Angeles, London: University of California Press, 2012.

FOUCAULT, Michel. Em defesa da sociedade. Tradução Maria Ermantina Galvão. 2. ed. São Paulo: WMF Martins Fontes, 2000.

: Segurança, território e população. Tradução E. Brandão. Rev. Trad. Claudia Berliner. 1. ed. São Paulo: Martins Fontes, 2008. (Coleção Trópicos)

JIMENO, Myrian. Emoções e Política: a vítima e a construção de comunidades emocionais. Mana - Estudos de Antropologia Social, v. 16, n. 1, 2010. p. 99-121.

\footnotetext{
${ }^{10}$ Tais aspectos, por exemplo, podem estar relacionados às indicações reiteradas para que os sujeitos não se encontrem, conversem, convivam ou guardem qualquer contato com as vítimas, pois, na verdade, independente das possibilidades de reconstrução, convivência não
}

LEITE, F.; LOPES, P. V. L. Serviços de educação e responsabilização para homens autores de violência contra mulheres: as possibilidades de intervenção em uma perspectiva institucional de gênero. In: P. V. L. LOPES, \& F. LEITE (Orgs). Atendimento a homens autores de violência doméstica: desafios à política pública. Rio de Janeiro: ISER - Instituto de Estudos da Religião, 2013.

\section{LOPES, Paulo Victor Leite. Homens}

Autores de Violência Doméstica: relações de gênero, formas cotidianas de governo e processos de formação de Estado. Tese (Doutorado em Antropologia) PPGAS/Museu Nacional, UFRJ, 2016.

LOPES, Paulo Victor Leite \& LEITE, Fabiana (Orgs.). Atendimento a homens autores de violência doméstica: desafios à política pública. Rio de Janeiro: Iser, 2013.

LUGONES, Maria Gabriela. Obrando em autos, obrando em vidas: formas e fórmulas de proteção judicial dos tribunais prevencionais de menores de Córdoba, Argentina, nos começos do século XXI. Rio de Janeiro: E-papers/Laced, 2012.

OLIVEIRA FILHO, João Pacheco. O Nosso Governo: os Ticuna e o Regime Tutelar. São Paulo: Marco Zero, 1989.

SOUZA LIMA, Antonio Carlos de. Um grande cerco de paz: poder tutelar, indianidade e formação do Estado no Brasil. Petrópolis: Vozes, 1995.

VIANNA, Adriana. Limites da Menoridade: tutela, família e autoridade em julgamento. Rio de Janeiro. Tese (Doutorado em Antropologia) PPGAS/Museu Nacional, UFRJ, 2002.

conflituosa ou até não boa relação entre os mesmos, o que se deseja é que não se demande, mais uma vez, o Estado em torno daquelas questões. 